\title{
Cooperative DNA-binding and sequence-recognition mechanism of aristaless and clawless
}

\section{Ken-ichi Miyazono ${ }^{1}$, Yuehua Zhi ${ }^{1}$, Yuriko Takamura', Koji Nagata', Kaoru Saigo ${ }^{2}$, Tetsuya Kojima ${ }^{3}$ and Masaru Tanokura ${ }^{1, *}$}

\begin{abstract}
${ }^{1}$ Department of Applied Biological Chemistry, Graduate School of Agricultural and Life Sciences, University of Tokyo, Bunkyo-ku, Tokyo, Japan, ${ }^{2}$ Department of Biophysics and Biochemistry, Graduate School of Science, University of Tokyo, Bunkyo-ku, Tokyo, Japan and

${ }^{3}$ Department of Integrated Biosciences, Graduate School of Frontier

Sciences, University of Tokyo, Kashiwa-city, Chiba, Japan
\end{abstract}

To achieve accurate gene regulation, some homeodomain proteins bind cooperatively to DNA to increase those site specificities. We report a ternary complex structure containing two homeodomain proteins, aristaless (Al) and clawless (CIl), bound to DNA. Our results show that the extended conserved sequences of the Cll homeodomain are indispensable to cooperative DNA binding. In the AlCll-DNA complex structure, the residues in the extended regions are used not only for the intermolecular contacts between the two homeodomain proteins but also for the sequence-recognition mechanism of DNA by direct interactions. The residues in the extended $\mathrm{N}$-terminal arm lie within the minor groove of DNA to form direct interactions with bases, whereas the extended conserved region of the C-terminus of the homeodomain interacts with Al to stabilize and localize the third $\alpha$ helix of the Cll homeodomain. This structure suggests a novel mode for the cooperativity of homeodomain proteins.

The EMBO Journal (2010) 29, 1613-1623. doi:10.1038/

emboj.2010.53; Published online 13 April 2010

Subject Categories: structural biology

Keywords: crystal structure; development; gene regulation; homeodomain

\section{Introduction}

Homeodomain proteins, which make up one of the most widespread superfamilies of eukaryotic DNA-binding proteins, regulate the transcription of various kinds of genes that are indispensable to development (Gehring et al, $1994 a, b)$. The homeodomain consists of 60 highly conserved amino acids and forms an N-terminal arm structure and the following three $\alpha$ helices. The homeodomain reads target DNA sequences using its N-terminal arm and the third helix from the minor and major groove of DNA, respectively (Qian et al, 1989; Wolberger et al, 1991; Klemm et al, 1994). Because of the high level of conservation of both the

\footnotetext{
*Corresponding author. Department of Applied Biological Chemistry, Graduate School of Agricultural and Life Sciences, University of Tokyo, 1-1-1 Yayoi, Bunkyo-ku, Tokyo 113-8657, Japan. Tel.: + 8135841 5165; Fax: + 8135841 8023;

E-mail: amtanok@mail.ecc.u-tokyo.ac.jp
}

Received: 13 October 2009; accepted: 8 March 2010; published online: 13 April 2010 amino-acid sequences and three-dimensional structures, homeodomain recognition sequences are highly similar to one another (Laughon, 1991). Although these high degrees of similarity would seem to conflict with the fact that homeodomain proteins regulate the expression of a large number of development-related genes with high specificity, homeodomain proteins resolve this paradox by cooperative binding with cofactors, including the other homeodomain proteins (White, 1994; Mann and Chan, 1996).

Some homeodomain proteins bind cooperatively to specific DNA sequences. MATa1 and MAT $\alpha 2$ are well-characterized homeodomain proteins from Saccharomyces cerevisiae that bind cooperatively to the sites upstream of haploidspecific genes and repress the expression of those genes (Goutte and Johnson, 1993). Although the DNA-binding affinity and specificity of MATa1 in the absence of MAT $\alpha 2$ are very low, the heterodimer of MATa1 and MAT $\alpha 2$ can regulate a number of genes with high specificity (Goutte and Johnson, 1993; Phillips et al, 1994). In the ternary complex structure of MATa1-MAT $\alpha 2-D N A$, a conserved C-terminal tail region of MAT $\alpha 2$ forms a short $\alpha$ helix and interacts with a hydrophobic patch between helix $\alpha 1$ and helix $\alpha 2$ of the MATa1 homeodomain (Li et al, 1995). This proteinprotein interaction is indispensable to the cooperative binding of these homeodomain proteins to minimize the overall energy cost of cooperative DNA binding (Ke and Wolberger, 2003). The other examples are cooperative binding of Hox homeodomain proteins and three amino-acid loop extension (TALE) family homeodomains (Chang et al, 1995; Mann and Chan, 1996; Neuteboom and Murre, 1997). The TALE family homeodomain, which includes Pbx1 (as well as Pbx2 and Pbx3) from human and Exd from Drosophila, possesses a TALE region between helix $\alpha 1$ and helix $\alpha 2$ that is involved in their interaction with Hox proteins (Bertolino et al, 1995). Cooperative DNA binding of the Hox protein with the TALE family homeodomain is dependent on a conserved YPWM motif located N-terminal to the Hox homeodomain (Knoepfler and Kamps, 1995). The three-dimensional structures of this type of complex (HoxB1-Pbx1-DNA (Piper et al, 1999), HoxA9-Pbx1-DNA (LaRonde-LeBlanc and Wolberger, 2003), Ubx-Exd-DNA (Passner et al, 1999), and Scr-ExdDNA (Joshi et al, 2007)) revealed that the YPWM motif conserved in the region N-terminal to the Hox homeodomain interacts directly with the hydrophobic pocket formed around the TALE region. Interaction of the YPWM motif with the Pbx1 or Exd homeodomain can increase the DNA-binding affinity of these homeodomains by stabilizing the DNA recognition helix $\alpha 3$ of $\mathrm{Pbx} /$ Exd. Furthermore, the sequence-specific structure of DNA is critical to the accurate sequence recognition of this type of homeodomain.

In this paper, we focused on the cooperativity of two homeodomain proteins, aristaless (Al) and clawless (Cll), from Drosophila melanogaster. These homeodomain proteins have an important function in Drosophila leg development. In the distalmost region, homeobox genes, al, Lim1, and cll 
(also known as C15), are expressed to specify the region, whereas a pair of Bar homeobox genes are expressed in its immediate neighbour (distal tarsus) (Campbell, 2005; Kojima et al, 2005). For the accurate differentiation of these regions, Bar expression is repressed by the cooperative mechanism of $\mathrm{Al}$ and $\mathrm{Cll}$ in the distalmost region. An earlier study showed that these two homeodomain proteins bind cooperatively to a specific DNA sequence, which has a consensus sequence of $5^{\prime}$-(T/C)TAATTAA(T/A) (T/A)G-3' and is included in the Bar enhancer element (Kojima et al, 2005). Both $\mathrm{Al}$ and $\mathrm{Cll}$ have several homologues in humans that are known to be involved in various aspects of embryogenesis, such as spleen, leg, craniofacial and neuronal development, and that are also known to cause T-cell acute lymphoblastic leukaemia, intestinal dysplasia, and neural tube defects (Hatano et al, 1991, 1997; Kennedy et al, 1991; Roberts et al, 1994, 1995; Zhao et al, 1994; Salvati et al, 1995; Shirasawa et al, 1997; Qu et al, 1999; Beverdam et al, 2001; Kanzler and Dear, 2001; Cheng et al, 2004; Kuijper et al, 2005). Among them, Cart1 (an Al homologue; sharing $75 \%$ sequence identity with $\mathrm{Al}$ in its homeodomain) and Hox11L1 (a Cll homologue; sharing 85\% sequence identity with $\mathrm{Cll}$ in its homeodomain) (Dear et al, 1993; Zhao et al, 1994) have already been examined for their cooperative DNA-binding activity. The Cart1-Hox11L1 complex, as well as the Al-Hox11L1 and Cart1-Cll complexes, was shown to bind specifically to the same sequences as the Al-Cll complex, indicating that this cooperative DNA-binding activity is a conserved feature of Al- and Cll-type homeodomain proteins (Kojima et al, 2005).

Al belongs to a paired class of homeodomain proteins that can bind cooperatively as homo- or heterodimers to a palindromic DNA sequence (Wilson et al, 1993). When the aminoacid sequence of $\mathrm{Al}$ and its homologous proteins were compared, only the homeodomain and OAR domain, which is thought to repress the DNA-binding affinity of $\mathrm{Al}$, were highly conserved (Figure 1A) (Brouwer et al, 2003). On the other hand, the conserved region of Cll was extended for 14 residues at the $\mathrm{N}$-terminus and 8 residues at the $\mathrm{C}$-terminus of its homeodomain (Figure 1B). The cooperative DNA-binding mechanism of these homeodomain proteins, particularly the function of the extended conserved region of the Cll homeodomain, has not been clarified.

To elucidate the structural basis of the cooperative DNAbinding mechanism of $\mathrm{Al}$ and $\mathrm{Cll}$, we first determined the minimal region of $\mathrm{Al}$ and that of $\mathrm{Cll}$ that are indispensable to the cooperative DNA-binding mechanisms of these proteins. We then tried to determine the homeodomain structures of $\mathrm{Al}, \mathrm{Cll}$, CART1, and Hox11L1, a binary complex structure of Al-DNA, and a ternary complex structure of Al-Cll-DNA to analyse the structural basis of the cooperativity of these proteins. In this study, we determined four structures by X-ray crystallography: that of the $\mathrm{Al}$ homeodomain, that of the Hox11L1 homeodomain, that of the binary complex of Al-DNA, and that of the ternary complex of Al-Cll-DNA. Our results show a novel ternary complex structure formation of homeodomain proteins that is distinguished from pre-existing structures.

\section{Results}

\section{Cooperative DNA-binding regions of $\mathrm{Al}$ and CII}

To identify the minimal regions of $\mathrm{Al}$ and Cll where each homeodomain protein binds cooperatively to DNA, we over- expressed constructs of $\mathrm{Al}$ and $\mathrm{Cll}$ (Al-HD (-5-63 in Figure $1 \mathrm{~A}), \mathrm{Cll}-\mathrm{N} 3 \mathrm{C} 3$ (N3-C3 in Figure 1B), Cll-N3C2 (N3-C2), Cll-N2C3 (N2-C2), Cll-N2C2 (N2-C2), Cll-N1C2 (N1-C2), and Cll-N2C1 (N2-C1)) and analysed their cooperative DNA-binding ability by EMSA (see Supplementary data). The EMSA results are shown in Figure 2. First, we confirmed the cooperative DNA binding of Al-HD and Cll$\mathrm{N} 3 \mathrm{C} 3$ constructed in this report. The Al homeodomain bound the target DNA by itself, whereas the Cll homeodomain bound the DNA weakly. In addition, Al-HD and Cll-N3C3 bound the DNA cooperatively in a sequence-specific manner (Figure 2A and B). Second, we shortened the Cll construct step-by-step from its $\mathrm{N}$-terminus and $\mathrm{C}$-terminus and analysed the cooperative DNA-binding ability of the resulting constructs. When the N2-N1 region of the Cll was deleted, Cll completely lost its cooperative DNA-binding ability with Al. This region is also indispensable to the cooperative DNA binding of human homologue of Cll, Hox11L1 (Supplementary Figure S1). When the $\mathrm{C} 1-\mathrm{C} 2$ region of the Cll was deleted, the cooperative DNA-binding ability of Cll was somewhat reduced (Figure 2C). Taken together, these results indicate that the cooperative-binding mechanism of $\mathrm{Al}$ and Cll requires the $\mathrm{Al}-\mathrm{HD}$ and $\mathrm{Cll}$ homeodomain with its extended $\mathrm{N}$-terminal and $\mathrm{C}$-terminal conserved regions (Figure 2D and E).

\section{The structure of the AI-CII-DNA complex}

The crystal structures of the Al homeodomain, the Hox11L1 homeodomain, the binary complex of Al-DNA, and the ternary complex of Al-Cll-DNA were determined at 1.00, $1.54,2.25$, and $2.70 \AA$ resolutions, respectively (Figure 3; Supplementary data). The structural model of the ternary complex contains residues $2-58$ of $\mathrm{Al},-15-63$ of $\mathrm{Cll}$, and $17 \mathrm{bp}$ of double-stranded DNA. In the ternary complex structure, the $\mathrm{Al}$ and $\mathrm{Cll}$ homeodomains bind DNA with a head-totail orientation, which is also observed in the structure of Hox-Pbx/Exd-DNA complexes (Passner et al, 1999; Piper et al, 1999; LaRonde-LeBlanc and Wolberger, 2003; Joshi et al, 2007): the C-terminal region of the Cll homeodomain lies adjacent to the N-terminal region of the Al homeodomain. The $\mathrm{Al}$ and $\mathrm{Cll}$ homeodomains observed in the ternary complex form a typical homeodomain structure consisting of an N-terminal arm structure followed by three $\alpha$ helices and bind to DNA using the N-terminal arm and the third $\alpha$ helix, in the manner of previously determined homeodomain-DNA complex structures. The third $\alpha$ helices of the $\mathrm{Al}$ and Cll homeodomains exist in the major groove of DNA in tandem, and each $\mathrm{N}$-terminal arm of the homeodomain follows the minor groove of DNA. In addition to these protein-DNA interactions, Cll also binds to DNA using its conserved residues located in the region $\mathrm{N}$-terminal to the homeodomain. In this study, we presented this region as an extended N-terminal arm. The extended N-terminal arm is well ordered in both structures of the Al-Cll-DNA ternary complexes (chains $\mathrm{ABCD}$ and $\mathrm{EFGH}$ ) in the asymmetric unit and contacts the minor groove of DNA as the N-terminal arm of the homeodomain, though the N-terminal arm of the homeodomain is frequently disordered in the structures of homeodomain-DNA complexes (Wolberger et al, 1991; Billeter et al, 1993; Hirsch and Aggarwal, 1995; Li et al, 1995; Tucker-Kellogg et al, 1997; Fraenkel and Pabo, 1998; Fraenkel et al, 1998; Passner et al, 1999; Piper et al, 1999; 

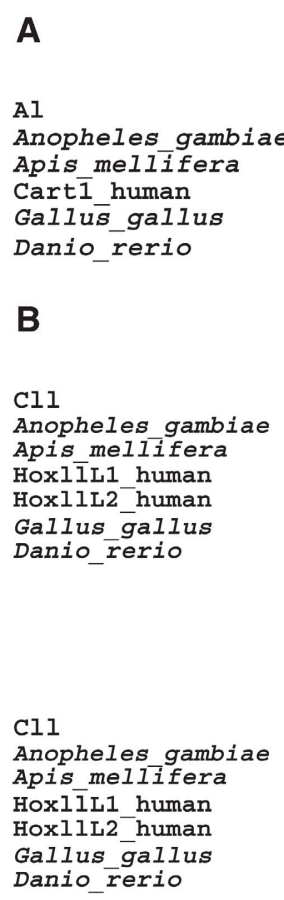

$\alpha 1$

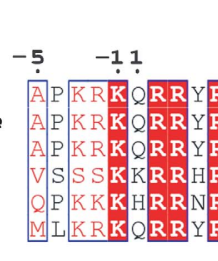

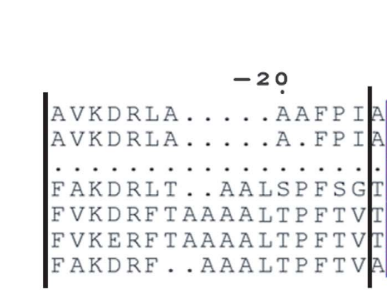

N3 10 lobelelel $\alpha 2$

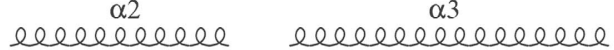
30

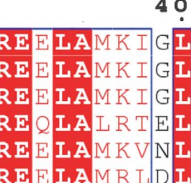

50
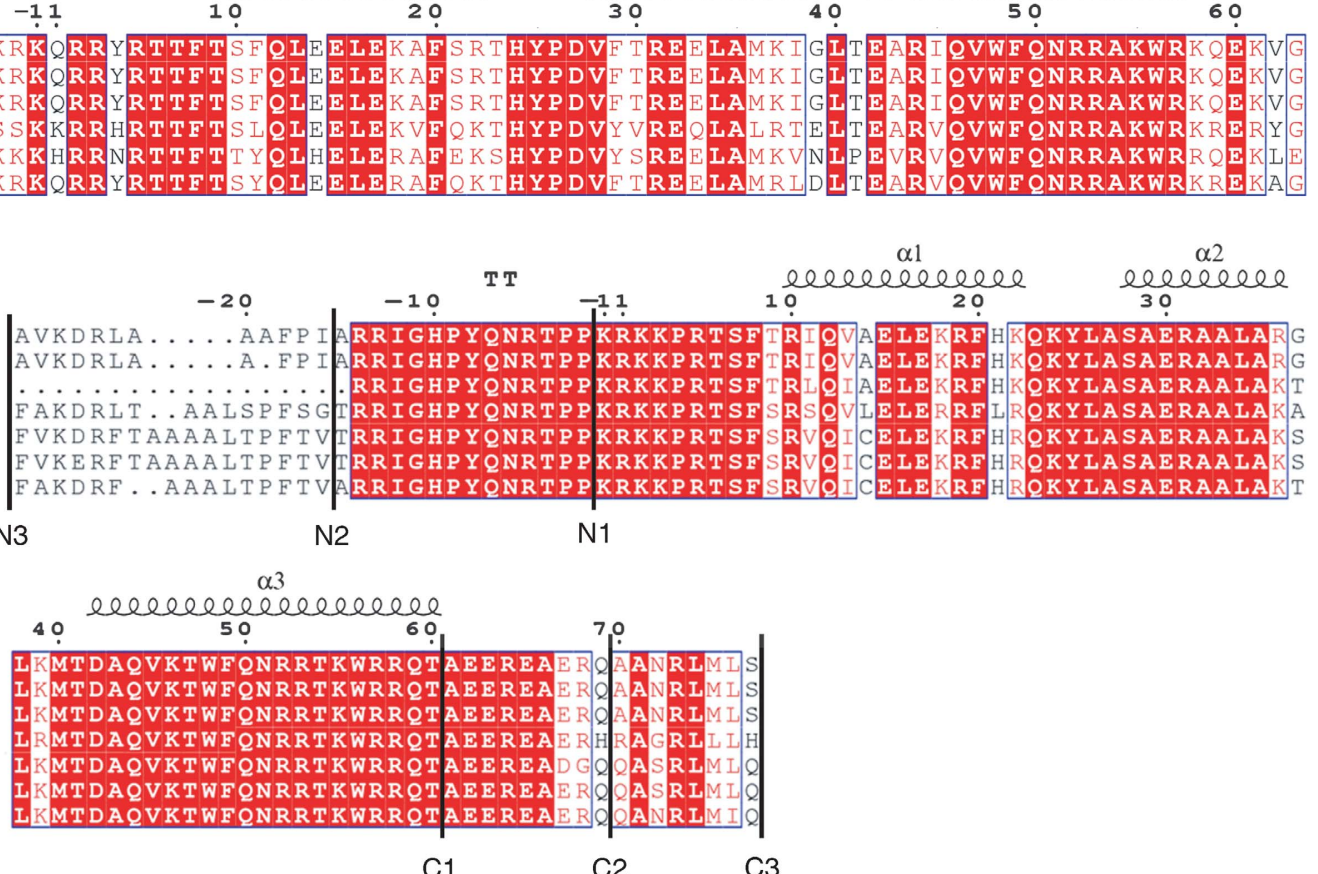

$\begin{array}{lll}\mathrm{C} 1 & \mathrm{C} 2 & \mathrm{C} 3\end{array}$

C

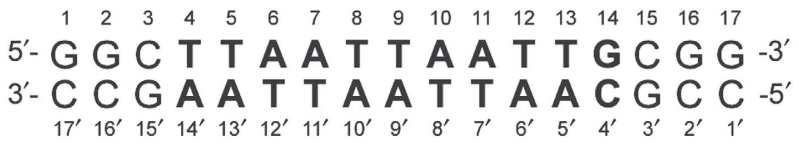

Figure 1 Sequences of $\mathrm{Al}, \mathrm{Cll}$, and the recognition site. (A) Alignment of the homeodomain sequences of $\mathrm{Al}$ and its homologues from other organisms (A. gambiae, A. mellifera, human (Cart1), Gallus gallus, and Danio rerio). The secondary structure assignment of Al is shown by helices ( $\alpha$ helix). The numbering follows the convention for the 60 residues of the homeodomain. (B) Alignment of the homeodomain sequences of Cll and its homologues from other organisms (A. gambiae, A. mellifera, human (Hox11L1 and Hox11L2), G. gallus, and D. rerio). Secondary structure assignments of $\mathrm{Cll}$ are shown by helices ( $\alpha$ helix) and TT ( $\beta$ turn). (C) Sequence of a dsDNA used for the structure determination of the Al-Cll-DNA complex. The recognition DNA sequence of $\mathrm{Al}$ and $\mathrm{Cll}$ is shown in bold. The bases are numbered from 1 to 17.

Hovde et al, 2001). The contact surface area between the DNA and the extended N-terminal arm is $960 \AA^{2}$, which is $37 \%$ of the total contact surface area between Cll-N2C3 and the DNA.

The extended N-terminal arm of Cll forms a unique conformation (Figure 3). It lies in the minor groove and wraps around the DNA. The four residues in the extended $\mathrm{N}$ terminal arm (Tyr-8, Gln-7, Asn-6, and Arg-5) are folded into a classical type I $\beta$ turn and form a hydrogen bond between Tyr- 8 and Arg-5. In this region, the side chains of Tyr- 8 and Arg- 5 in the $\beta$ turn and His- 10 are inserted into the minor groove of DNA.

The structure of the homeodomain region of each protein was not modified by the formation of the ternary complex. The r.m.s.d. of the Al homeodomain before and after the ternary complex formation was $0.4 \AA$ in the 51 aligned $C \alpha$ positions (Supplementary Figure S3A). In the structure of the Al homeodomain, the length of the third $\alpha$ helix is extended by 1 residue in the ternary complex. The r.m.s.d. between the Cll homeodomain in the ternary complex and the Hox11L1 homeodomain was $0.4 \AA$ in the aligned $53 \mathrm{C} \alpha$ atom positions (Supplementary Figure S3B). In the structure of the Cll homeodomain, the length of the third $\alpha$ helix is longer than that of the Hox11L1 homeodomain by one residue.

\section{DNA sequence-recognition mechanism of Al and CII}

$\mathrm{Al}$ and $\mathrm{Cll}$ are thought to regulate Bar expression by directly binding to sequences in the Bar enhancer region, which are fit to the $11 \mathrm{bp}$ consensus sequences, including $5^{\prime}-\mathrm{T}_{4} \mathrm{~T}_{5} \mathrm{~A}_{6} \mathrm{~A}_{7} \mathrm{~T}_{8} \mathrm{~T}_{9} \mathrm{~A}_{10} \mathrm{~A}_{11} \mathrm{~T}_{12} \mathrm{~T}_{13} \mathrm{G}_{14} \mathbf{3}^{\prime}$ (Kojima et al, 2005). The sequence-recognition mechanisms by $\mathrm{Al}$ and $\mathrm{Cll}$ observed in this study are summarized in Figure 4A. The $\mathrm{Al}$ homeodomain forms a set of conserved DNA contacts that have been observed in other homeodomain-DNA complex structures (Figure 4B). Al recognizes the $5^{\prime}$ $\mathrm{T}_{4} \mathrm{~T}_{5} \mathrm{~A}_{6} \mathrm{~A}_{7} \mathrm{~T}_{8} \mathrm{~N}_{9} \mathrm{~A}_{10}-3^{\prime}$ sequence in the ternary complex. The first three bases of the sequence $\left(5^{\prime}-\mathrm{T}_{4} \mathrm{~T}_{5} \mathrm{~A}_{6}-3^{\prime}\right)$ are recognized by the N-terminal arm residues, Arg3 and Arg5, from the minor groove of DNA. The Arg3 forms a hydrogen bond with the $\mathrm{O} 2$ atom of Thy12' (the counterpart of Ade6; see Figure 1C), whereas Arg5 forms a pair of hydrogen bonds with the $\mathrm{O} 2$ atom of Thy5 and the $\mathrm{N} 3$ atom of Ade14'. In the major groove, the last four bases $\left(5^{\prime}-\mathrm{A}_{6} \mathrm{~A}_{7} \mathrm{~T}_{8} \mathrm{~N}_{9} \mathrm{~A}_{10} \mathrm{3}^{\prime}\right)$ are recognized by the residues in the third $\alpha$ helix of the $\mathrm{Al}$ homeodomain, especially by the invariant bidentate hydrogen bonding between the highly conserved Asn51 residue and the adenine base (Ade7). In addition, Al recognizes three bases-Ade6, Thy8, and Thy8'-from the major groove of DNA using Asn51, Val47, and Gln50, respectively, by hydrogen bonding and/or van der Waals contacts. 

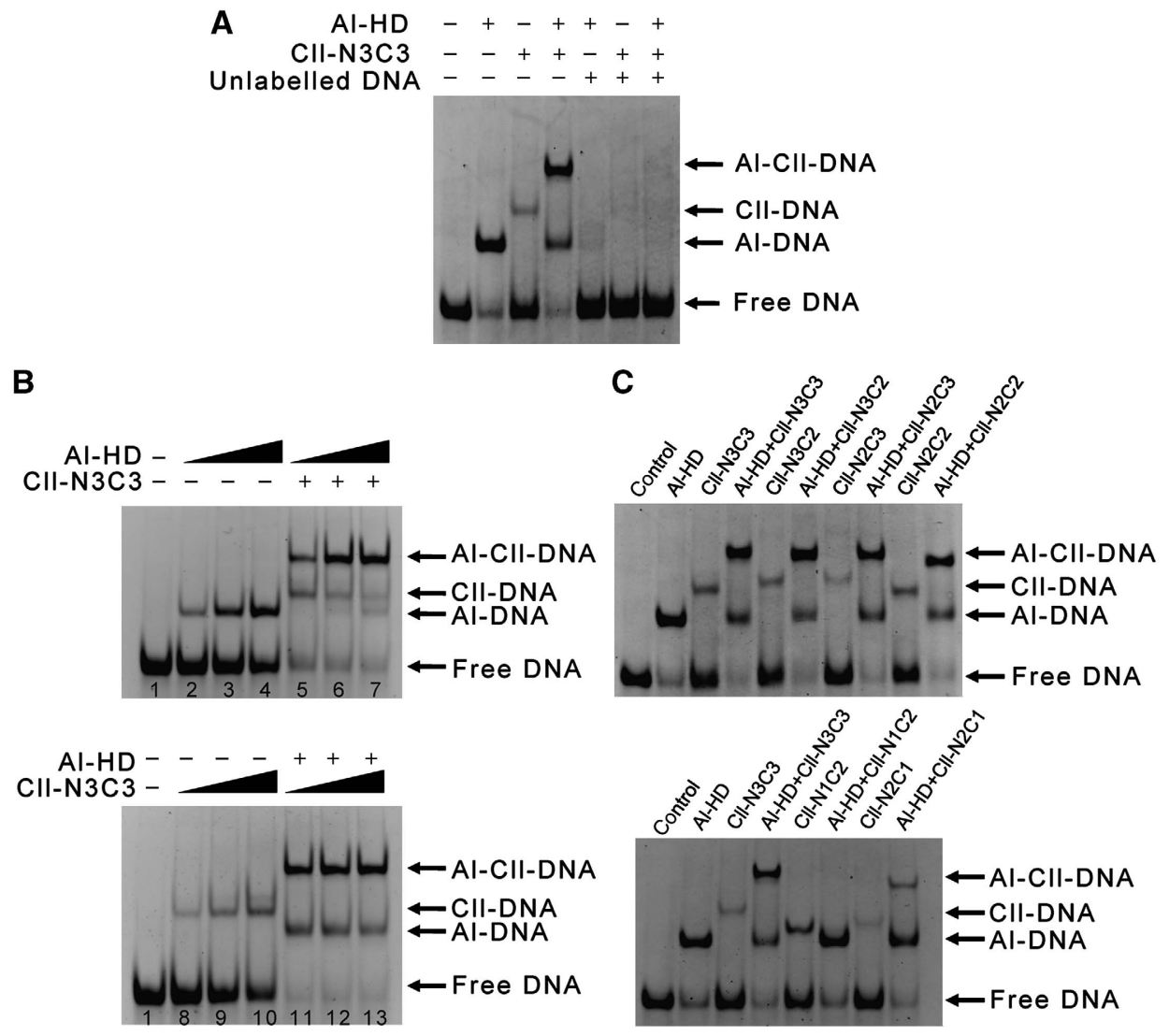

D

\begin{tabular}{cl} 
Protein & $K_{\mathrm{D}}\left(10^{-7} \mathrm{M}\right)$ \\
\hline Al-HD & $2.76 \pm 0.37$ \\
Cll-N2C2 & $66.9 \pm 9.9$ \\
Al-HD with Cll-N2C2 & $1.65 \pm 0.34$ \\
Cll-N3C3 with Al-HD & $7.32 \pm 0.66$ \\
Cll-N3C2 with Al-HD & $5.83 \pm 0.92$ \\
Cll-N2C3 with Al-HD & $7.71 \pm 1.54$ \\
Cll-N2C2 with Al-HD & $8.17 \pm 2.26$ \\
\hline
\end{tabular}

E

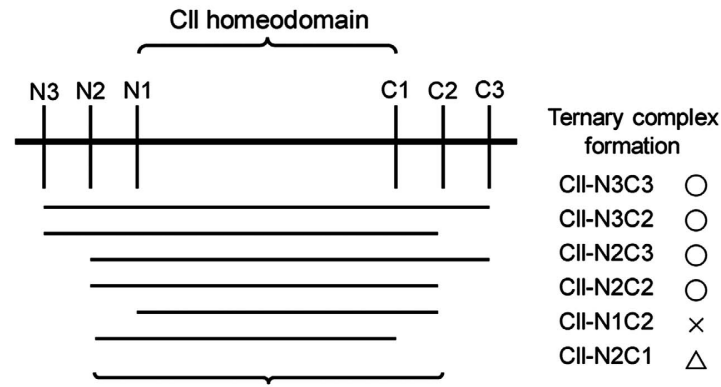

Minimum region for cooperative DNA-binding mechanism (N2-C2)

Figure 2 EMSA analysis. (A) Sequence-specific DNA binding of Al-HD and Cll-N3C3. In all, 10 pmol of Al-HD, 20 pmol of Cll-N3C3, and 2 pmol of FITC-labelled dsDNA were used for each binding reaction. (B) Cooperative DNA binding of Al-HD and Cll-N3C3. The following Al and Cll constructs were added to each binding reaction-lane 1: no protein; lanes 2, 3, and 4: 1.25, 2.50, and 5.00 pmol of Al-HD, respectively; lanes 5, 6, and 7: 1.25, 2.50, and $5.00 \mathrm{pmol}$ of Al-HD, respectively, and $260 \mathrm{pmol}$ of Cll-N3C3; lanes 8, 9, and 10: 16.3, 32.6, 65.2 pmol of Cll$\mathrm{N} 3 \mathrm{C} 3$, respectively; lanes 11, 12, and 13: 16.3, 32.6, $65.2 \mathrm{pmol}$ of $\mathrm{Cll}-\mathrm{N} 3 \mathrm{C} 3$, respectively, and 100 pmol of Al-HD. Each binding reaction contains 2 pmol of FITC-labelled dsDNA. (C) Cooperative DNA-binding affinities of Cll constructs (Cll-N3C3, Cll-N3C2, Cll-N2C3, Cll-N2C2, Cll-N1C2, and Cll-N2C1) with Al-HD. In all, 10 pmol of Al-HD, 20 pmol of Cll constructs, and 2 pmol of FITC-labelled dsDNA were used for each binding reaction. (D) Binding affinities $\left(K_{\mathrm{D}} \mathrm{S}\right)$ of the indicated proteins. (E) Summary of the EMSA analysis. The N2-C2 region is required for the cooperative DNA binding with Al-HD.

Cll recognizes the $5^{\prime}-\mathrm{T}_{8} \mathrm{~T}_{9} \mathrm{~A}_{10} \mathrm{~A}_{11} \mathrm{~T}_{12} \mathrm{~T}_{13} \mathrm{G}_{14}-3^{\prime}$ sequence, which overlaps with the recognition sequence of Al. The base-recognition mechanism of the Cll homeodomain is also similar to that of the typical homeodomain (Figure 4C). Arg5 in the $\mathrm{N}$-terminal arm is inserted into the minor groove of the DNA and forms two hydrogen bonds with two bases (Ade10' and Thy9) to recognize these sequences. The three residues (Thr47, Gln50, and Asn51) of the third $\alpha$ helix interact directly with bases from the major groove of the DNA to recognize the $5^{\prime}-\mathrm{A}_{10} \mathrm{~A}_{11} \mathrm{~T}_{12} \mathrm{~N}_{13} \mathrm{G}_{14}$ - $3^{\prime}$ sequence. In addition to these typical homeodomain-DNA interactions, the extended $\mathrm{N}$-terminal arm of Cll interacts directly with the last three bases of the recognition sequence $\left(5^{\prime}-\mathrm{T}_{12} \mathrm{~T}_{13} \mathrm{G}_{14}-3^{\prime}\right)$ to improve the sequence specificity and DNA-binding affinity of Cll (Figure 4D). The three residues, His-10, Tyr-8, and Arg-5, lie within the minor groove of DNA and interact directly with the bases and the sugar groups of the recognition sequence. His-10 is inserted into the minor groove of DNA and forms a direct hydrogen bond with the N3 atom of Gua14 at a distance of $3.03 \AA$. The guanidium nitrogen atom of Arg-5 lies deeper within the minor groove of DNA to form a hydrogen bond with the N3 atom of Ade6' at a distance of $2.89 \AA$. In addition, the guanidium nitrogen of Arg-5 also lies next to the $\mathrm{O} 2$ atoms of Thy 13 and Ade5' at distances of 3.42 


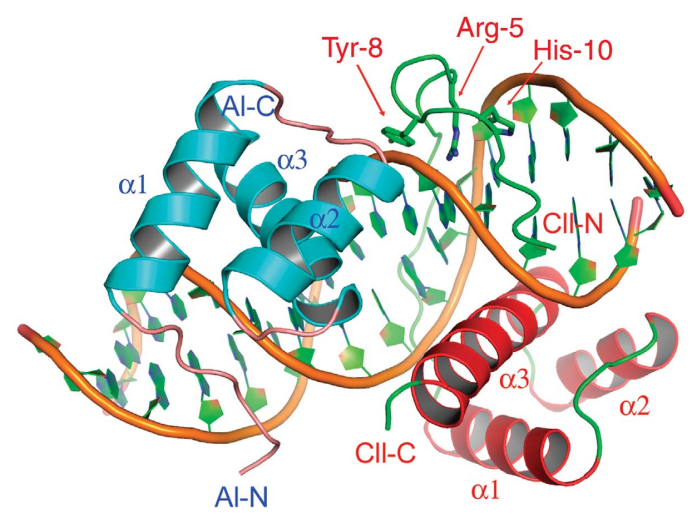

Figure 3 Structure of the ternary complex of Al-Cll-DNA. Overall structure of Al-Cll-DNA. Al and Cll are coloured cyan and red, respectively. Secondary structure assignments are labelled on the ribbon model. The side chains of His-10, Tyr-8, and Arg-5 of Cll are shown by a stick model.

and $3.73 \AA$, respectively, and may be involved in the recognition of these bases. On the other hand, Tyr- 8 forms van der Waals contacts with the sugar groups of Thy $7^{\prime}$ and Thy $8^{\prime}$, though the residues are not involved in the sequence-recognition mechanisms through direct interaction with the bases.

\section{Characteristic DNA structure modification in the AI-CII-DNA complex}

In the ternary complex structure of Al-Cll-DNA, the DNA structure was partially modified from the typical B-form structure by the binding of two homeodomain proteins. The most characteristic feature is that the minor groove of DNA is largely expanded around the region to which the extended $\mathrm{N}$ terminal arm of Cll binds (Figure 5A and $\mathrm{B}$ ). The average minor groove width of the $5^{\prime}-\mathrm{T}_{9} \mathrm{~A}_{10} \mathrm{~A}_{11} \mathrm{~T}_{12} \mathrm{~T}_{13}-3^{\prime}$ region is 7.7 $\AA$. In general, AT-rich regions often lead to narrow minor grooves due to negative propeller twisting (Crothers and Shakked, 1999). As expected, the average value for the propeller twist in this region is $-12.2^{\circ}$. Although the propeller twisting is negative, the minor groove is expanded by three inter-base pair steps $\left(\mathrm{T}_{9} \mathrm{pA}_{10}, \mathrm{~T}_{12} \mathrm{pT}_{13}\right.$, and $\mathrm{T}_{13} \mathrm{pG}_{14}$ steps) with large roll values $\left(12.0^{\circ}, 11.4^{\circ}\right.$, and $4.9^{\circ}$, respectively). The large positive roll value is expected to lead to a wide minor groove.

The expanded minor groove is stabilized by the residues of the $\mathrm{Al}$ homeodomain (Figure 5C). The phosphate group of Thys' is tightly stabilized by the hydrogen-bonding network between the phosphate group and Tyr25, Arg53, and Arg57 of Al. The analysis of the temperature factor of the ternary complex structure shows that this region possesses the lowest $B$ factor in the complex (Supplementary Figure S4).

The minor groove width in this region is also expanded in the structure of the Al-DNA complex (Figure 5A and B). In the binary complex, residues of the Al homeodomain form several hydrogen bonds with the phosphate group of DNA in this region (Figure 5D). The oxygen atom of $\mathrm{Gln} 46$ of $\mathrm{Al}$ forms a hydrogen bond with the phosphate group of Cyt2' (the counterpart of Gua13; see Supplementary Figure S2D) at a distance of $2.92 \AA$. In addition, the side chains of Tyr 25 , Arg53, and Arg57 of Al form a strict hydrogen-bonding network with the phosphate group of Thy $4^{\prime}$ at distances of 2.54 , 2.81, and $2.48 \AA$, respectively. The side chain of Arg57 also forms a hydrogen bond with the phosphate group of Ade $5^{\prime}$ at a distance of $2.63 \AA$.

\section{Intermolecular interactions between Al and Cll on target DNA}

The intermolecular interactions between $\mathrm{Al}$ and $\mathrm{Cll}$ are focused on the extended conserved region of the Cll homeodomain (Figure 6A). In the Al-Cll-DNA complex, two intermolecular interaction sites (sites 1 and 2) are observed. Site 1 consists of intermolecular interactions between the $\mathrm{Al}$ homeodomain and the extended N-terminal arm of Cll. In this site, Arg-14 of Cll forms a salt bridge with Glu32 of $\mathrm{Al}$ at a distance of $2.69 \AA$ (Figure 6B). In addition, Ile-12 of Cll has hydrophobic interactions with Val28 and Phe29 of Al. Gln-7 of Cll also has a hydrophobic interaction with Tyr25 of Al. On the other hand, site 2 consists of intermolecular interactions around the $\mathrm{C}$-terminal residues of the Cll homeodomain. In this site, Glu62 of Cll forms a salt bridge with Arg44 of $\mathrm{Al}$ at a distance of $3.60 \AA$ (Figure 6C). Glu62 may also form a watermediated hydrogen-bonding network with Thr41 of Al, though the coordinates of the water molecules could not be determined due to the low-resolution data.

\section{Mutation analysis of the extended conserved region of the CII homeodomain}

To elucidate the importance of the extended conserved region of the Cll homeodomain, we overexpressed alanine mutants and analysed the cooperative DNA-binding affinities with Al-HD by EMSA. When we mutated the residues in the extended N-terminal arm, the His-10Ala, Tyr-8Ala, and Arg5Ala mutants lost the cooperative DNA-binding affinity with $\mathrm{Al}-\mathrm{HD}$, though the other mutants bound to the target DNA cooperatively with Al-HD (Figure 7A). These three residues undergo characteristic interactions with DNA and are involved in the DNA's recognition mechanism. The intermolecular interactions of the residues in the extended $\mathrm{N}$-terminal arm of Cll (His-10, Tyr-8, and Arg-5) are indispensable to the cooperative DNA binding of $\mathrm{Al}$ and $\mathrm{Cll}$. When we mutated the Glu62, which forms a salt bridge with the Al homeodomain, the cooperative-binding affinity of $\mathrm{Al}$ and Cll was reduced (Figure $7 \mathrm{~B}$ and $\mathrm{C}$ ). The $K_{\mathrm{D}}$ value of the cooperative DNA binding of the Cll-N2C3 Glu62Ala mutant is nearly identical to that of Cll-N2C1, which is a deletion mutant of the extended conserved residues in the $\mathrm{C}$-terminal region of the Cll homeodomain. The salt bridge in the extended conserved region of the C-terminus of the Cll homeodomain is also important for the cooperative DNA binding of $\mathrm{Al}$ and $\mathrm{Cll}$.

\section{Discussion}

\section{DNA structural characteristics that are indispensable to the cooperative DNA binding of Al and CII}

DNA structure is known to affect the specific sequencerecognition mechanism of homeodomain proteins. In the HoxA9-Pbx1-DNA structure, a series of contacts mediated by the HoxA9 N-terminal arm residues Pro7 and Tyr8, and a first helix residue Thr13 compress the minor groove of DNA and allow an additional sequence-recognition mechanism by Gln51 of HoxA9 (LaRonde-LeBlanc and Wolberger, 2003). On the other hand, one of the Hox proteins, Scr, recognizes the sequence-specific structure of DNA (Joshi et al, 2007). The DNA structure is slightly modified depending on its sequence. 

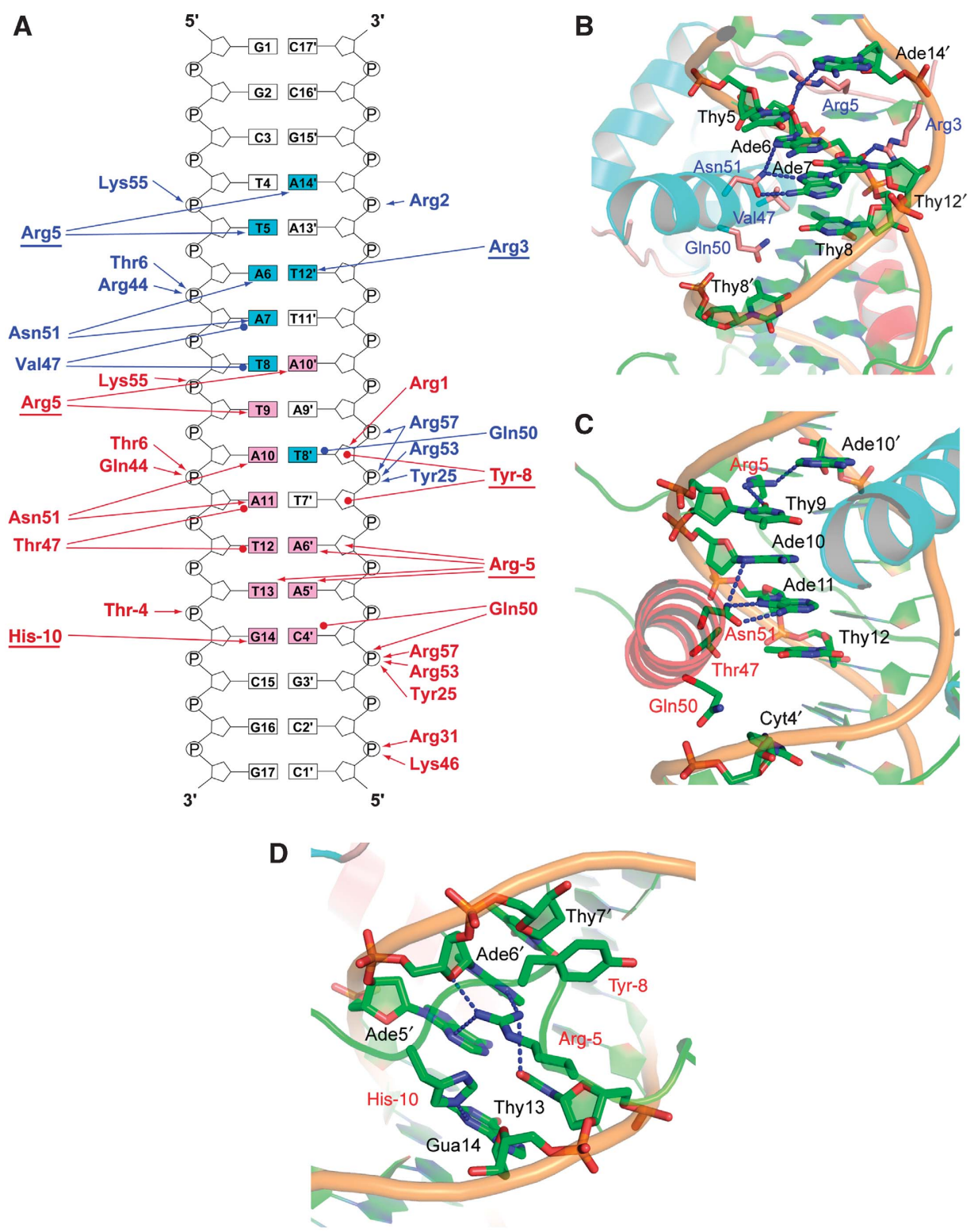

Figure 4 Protein-DNA contacts. (A) Base recognition mode of $\mathrm{Al}$ and Cll. Residues from $\mathrm{Al}$ and Cll are coloured blue and red, respectively. Bases recognized by Al and $\mathrm{Cll}$ are coloured cyan and red, respectively. Hydrogen bonds are indicated with arrows, and van der Waals contacts are shown as lines terminating in a circle. Residues interacting with DNA from a minor groove are underlined. (B) DNA sequence-recognition mechanism of the Al homeodomain. Residues involved in the sequence-recognition mechanisms are shown by a stick model. Hydrogen bonds are shown by blue dotted lines. Residues from Al are labelled in blue and bases are labelled in black. (C) DNA sequence-recognition mechanism of the Cll homeodomain. Residues from Cll are labelled in red. (D) DNA sequence-recognition mechanism of the extended N-terminal arm of Cll.

Consecutive ApA, TpT, or ApT base pair steps are known to result in a narrow minor groove due to negative propeller twisting that is stabilized by inter-base pair interactions in the major groove (Crothers and Shakked, 1999). In the ternary complex structure of Scr-Exd-DNA (Joshi et al, 2007), His-12 and Arg3 of Scr are inserted into a narrow region of the minor groove and recognize the sequence-specific structure of DNA to serve a paralog-specific function.

Contrary to this general tendency between sequence and structure, the minor groove region of the DNA where the extended N-terminal arm of Cll binds is greatly expanded from a typical B-form DNA, though the DNA sequence of this region consists of $\mathrm{ApA}$, TpT, or ApT base pair steps $\left(5^{\prime}-\mathrm{T}_{9} \underline{\mathrm{A}}_{10} \underline{\mathrm{A}}_{11} \underline{\mathrm{T}}_{12} \underline{\mathrm{T}}_{13} \mathrm{G}_{14}-\mathrm{C}^{\prime}\right)$. This characteristic substructure suggests that the structure of the DNA is highly affected by the protein-DNA contacts. In the structure of the Al-Cll-DNA complex, the DNA kinks at the $\mathrm{T}_{9} \mathrm{pA}_{10}, \mathrm{~T}_{12} \mathrm{pT}_{13}$, and $\mathrm{T}_{13} \mathrm{pG}_{14}$ steps to increase the minor groove width. As the expanded minor groove is also observed in the binary complex structure of Al-DNA, the expansion of the minor groove would be induced by the binding of the $\mathrm{Al}$ homeodomain to the DNA. In the structure of $\mathrm{Al}-\mathrm{DNA}, \mathrm{Al}$ forms a set of conserved DNA contacts that have been observed in other homeodomainDNA complex structures to recognize the sequence (Supplementary data). In addition to the general contacts, the residues of $\mathrm{Al}$ (Tyr25, Gln46, Arg53, and Arg57) form direct hydrogen bonds with the phosphate group of DNA in the expanded minor groove region. The expansion of the minor groove would be induced by these interactions. The residues expanding the minor groove are highly conserved 
A

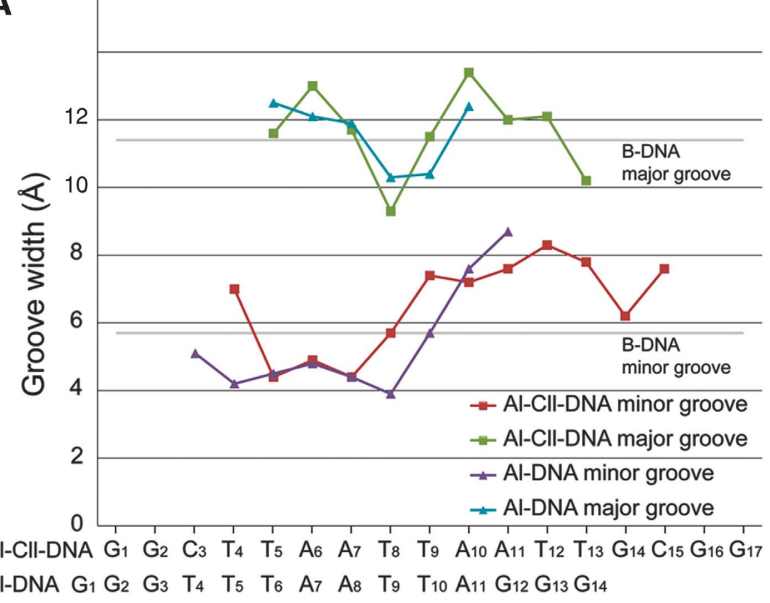

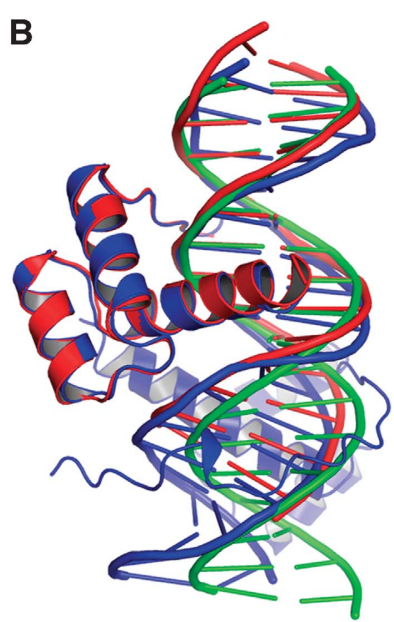
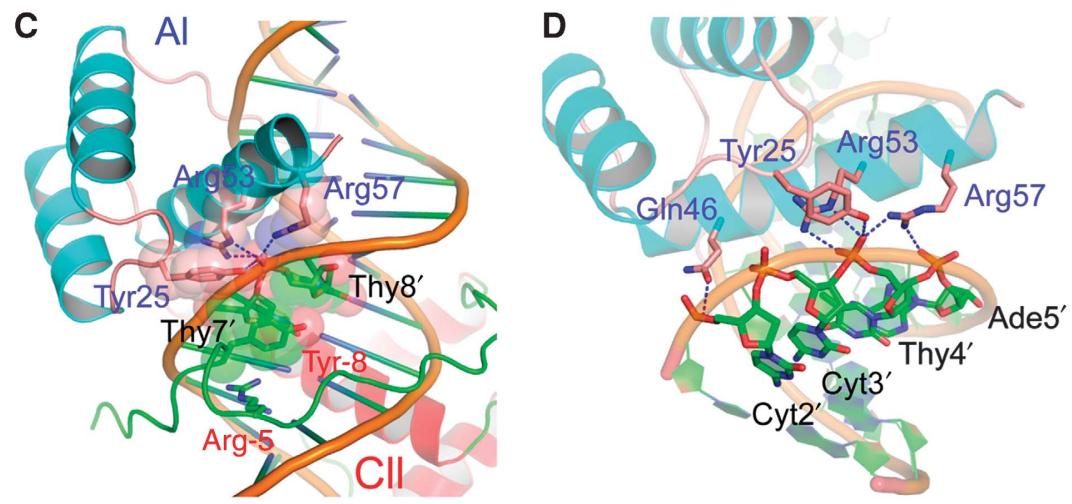

Figure 5 Characteristic DNA structure. (A) Plots of major and minor groove widths as a function of the DNA sequence. Horizontal grey lines indicate the average values for B-form DNA. Only the sequence of the top strand is shown. (B) Superposition of the binary complex of Al-DNA (red), the ternary complex of Al-Cll-DNA (blue), and $17 \mathrm{bp}$ of B-form DNA (green). (C) Expanded minor groove of DNA in the Al-Cll-DNA complex. Each residue is shown by a stick and sphere model. $\mathrm{Al}$ and $\mathrm{Cll}$ are coloured cyan and red, respectively. (D) Expanded minor groove of DNA in the Al-DNA complex. Al is coloured cyan.

among the homologous proteins of $\mathrm{Al}$ (Figure 1A). The high conservation may suggest the importance of the minor groove expansion mechanism of these proteins.

The residues of the extended $\mathrm{N}$-terminal arm of Cll interact directly with sugar and base groups of the DNA in the expanded minor groove region. These interactions increase the binding affinity and sequence specificity of Cll (Figures 2 and 4). The expansion of the minor groove supports the interactions between the residues in the extended $\mathrm{N}$-terminal arm and DNA from the minor groove side by increasing the contact area of the minor groove side. As the expansion of the minor groove is induced by the Al homeodomain, the interaction from the minor groove at this site would not occur by the binding of Cll solely to the target sequence of the DNA. The observation that Cll, by itself, binds the target sequence with low affinity supports the importance of the intermolecular interaction between the expanded minor groove and the extended N-terminal arm.

\section{Importance of the extended $\mathbf{N}$-terminal arm for cooperative binding}

The N-terminal arm of the Cll homeodomain is extended for 14 residues compared with typical homeodomains. In this paper, we showed that this extension of the $\mathrm{N}$-terminal arm is indispensable to the cooperative DNA-binding mechanism of $\mathrm{Al}$ and $\mathrm{Cll}$. In the ternary complex structure of Al-Cll-DNA, the extended $\mathrm{N}$-terminal arm of the $\mathrm{Cll}$ forms a typical type I $\beta$ turn and recognizes the DNA sequence through direct interactions. Although characteristic secondary structure formations, such as a $\beta$ turn or $3_{10}$ helix, and sequence-recognition mechanisms using this region have been reported earlier (Passner et al, 1999; Piper et al, 1999; Slupsky et al, 2001; Joshi et al, 2007), the reason why this region is important for the cooperativity is different.

In the structures of Hox-Pbx/Exd-DNA, a Hox-specific YPWM motif folds into the $3_{10}$ helix or type I $\beta$ turn. But the substructure is used for the intermolecular interactions with Pbx/Exd. The YPWM motif of Hox homeodomains interacts with the hydrophobic pocket formed around the TALE region of the Pbx/Exd homeodomain using an invariant tryptophan residue. On the other hand, the $\beta$-turn formation in the extended N-terminal arm of Cll assists the structure and sequence recognition mechanism by the extended $\mathrm{N}$-terminal arm. In the Al-Cll-DNA complex, the first residue of the $\beta$ turn (Tyr-8) is inserted into the expanded minor groove region and interacts with the sugar group of Thy $7^{\prime}$ and Thy $8^{\prime}$ to recognize the expanded minor groove structure. This proteinDNA interaction would be important to recruit the residues around the $\beta$ turn, such as His-10 and Tyr-8, to the expanded minor groove. These two residues are indispensable to the sequence recognition mechanism of Cll from the minor groove. 

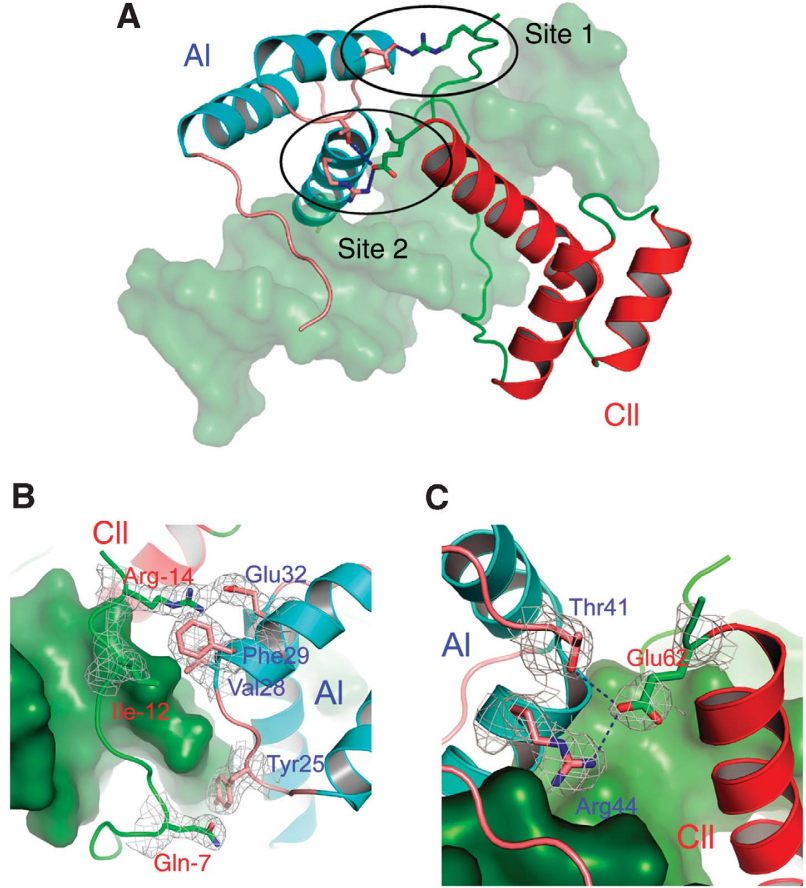

Figure 6 Intermolecular interactions between $\mathrm{Al}$ and Cll. (A) Intermolecular interaction sites observed in the ternary complex structure of Al-Cll-DNA. Al and Cll are coloured cyan and red, respectively. Interaction sites are indicated by black circles (site 1 and site 2). (B, C) Intermolecular interactions observed in sites 1 and 2 . Ion pairs and hydrogen bonds are shown by a blue dotted line. Residues involved in the intermolecular contacts are shown by a stick model. Residue numbers of $\mathrm{Al}$ and $\mathrm{Cll}$ are coloured blue and red, respectively. A grey mesh indicates the $2 F_{\mathrm{o}}-F_{\mathrm{c}}$ map contoured at $1.0 \sigma$. DNA is shown with a green surface model.

Although protein-DNA interactions from the minor groove side using histidine and arginine residues were also observed in the structure of the Scr-Exd-fkh250 complex (Joshi et al, 2007), these residues do not interact directly with the bases but recognize the DNA sequence using the sequence-specific shape of the DNA: the guanidium group of arginine and the imidazole ring of histidine lie in approximately the same plane and are inserted into the narrow region of the minor groove to recognize the shape of the DNA. In contrast, we observed direct interactions between the residues and bases in the structure of Al-Cll-DNA. These two residues approach and come into closer proximity to the base groups of DNA than do the residues of the Scr-Exd-DNA complex from the minor groove side and increase the sequence specificity and binding affinity of the cooperative DNA binding of $\mathrm{Al}$ and $\mathrm{Cll}$ by direct interactions. In most cases, the extended conserved regions of homeodomains are used for the intermolecular interactions or the recognition of the sequence-specific structure of the minor groove of the DNA. The direct recognition of the DNA sequence from the minor groove using the extended $\mathrm{N}$-terminal arm is a structural characteristic identified for the first time in this report.

\section{Intermolecular interactions between two homeodomain proteins}

Intermolecular interactions between two homeodomain proteins support the cooperative DNA binding (Stark and Johnson, 1994; Chang et al, 1995; Li et al, 1995;
A

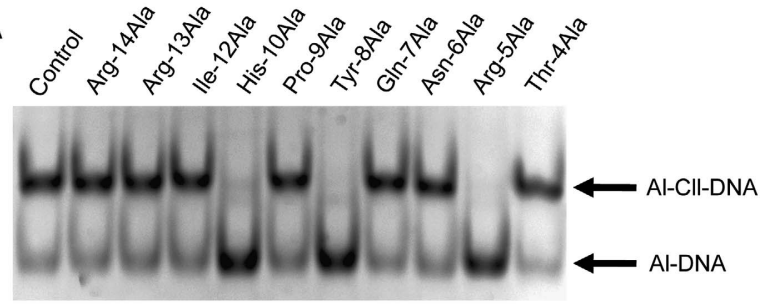

B
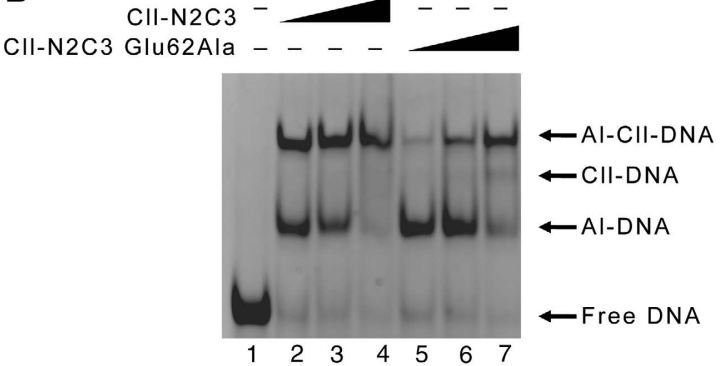

\begin{tabular}{ccc} 
C & Protein & $K_{\mathrm{D}}\left(10^{-7} \mathrm{M}\right)$ \\
\cline { 2 - 3 } CII-N2C1 with Al-HD & $20.3 \pm 2.3$ \\
CII-N2C3 Glu62Ala with Al-HD & $21.4 \pm 2.5$ \\
\hline
\end{tabular}

Figure 7 Mutation analysis. (A) EMSA analysis of the alanine mutants of Cll-N2C3. His-10Ala, Tyr-8Ala, and Arg-5Ala lost the ability to bind cooperatively with $\mathrm{Al}$. In all, $10 \mathrm{pmol}$ of $\mathrm{Al}$ construct, $20 \mathrm{pmol}$ of Cll constructs, and 2 pmol of FITC-labelled dsDNA were used for each binding reaction. (B) Cooperative DNA binding of CllN2C3 and Cll-N2C3 Glu62Ala with Al-HD. The following Al-HD and Cll constructs were added to each binding reaction-lane 1: no protein; lanes 2, 3, and 4: $100 \mathrm{pmol}$ of $\mathrm{Al}-\mathrm{HD}$ and 17.5, 35.0, and $70.0 \mathrm{pmol}$ of Cll-N2C3, respectively; lanes 5,6 , and 7: $100 \mathrm{pmol}$ of $\mathrm{Al}-\mathrm{HD}$ and $17.5,35.0$, and $70.0 \mathrm{pmol}$ of Cll-N2C3 Glu62Ala, respectively. Each binding reaction contains 2 pmol of FITC-labelled dsDNA. (C) Binding affinities $\left(K_{\mathrm{D}} \mathrm{s}\right)$ of the indicated proteins.

Neuteboom and Murre, 1997; Passner et al, 1999; Piper et al, 1999; LaRonde-LeBlanc and Wolberger, 2003; Joshi et al, 2007). In the structure of Al-Cll-DNA, two homeodomain proteins interact with each other at two sites (Figure 6). At site 1, the extended N-terminal arm of Cll interacts with the $\alpha 1-\alpha 2$ loop and $\alpha 2$ of the Al homeodomain. In the Al-Cll-DNA complex, the three residues in the extended N-terminal arm, His-10, Tyr-8, and Arg-5, form remarkable contacts with the minor groove of DNA. These interactions are indispensable to the cooperative DNA binding of $\mathrm{Al}$ and $\mathrm{Cll}$. The intermolecular interaction between $\mathrm{Al}$ and $\mathrm{Cll}$ around the extended N-terminal arm of Cll may help to recruit the three residues to the correct position by the support of Al, which can bind to DNA more tightly than Cll, though single mutants of the residues of $\mathrm{Al}$ involved in the protein-protein interface did not show any significant decrease of the cooperative DNA-binding ability.

Meanwhile, intermolecular interactions at site 2 seem to stabilize and localize the third $\alpha$ helix of the Cll homeodomain. Although the structure of the Cll homeodomain in the ternary complex is nearly identical to that of the Hox11L1 homeodomain, the existence of the extended conserved residues of the $\mathrm{C}$-terminal region of the $\mathrm{Cll}$ homeodomain is important for the maximum cooperative DNA-binding affinity with $\mathrm{Al}$ (Figures $2 \mathrm{C}, \mathrm{D}$ and $7 \mathrm{C}$ ). The $K_{\mathrm{D}}$ values of the Cll-N2C3 Glu62Ala mutant and Cll-N2C1 indicate that the 
existence of the glutamic acid residue at this position is critical for the maximum cooperative DNA-binding mechanism using the extended conserved residues in the C-terminal region of the Cll homeodomain. In this region, Glu62 of Cll forms a salt bridge with Arg44 of the Al homeodomain at a distance of $3.60 \AA$. Al seems to attract the third $\alpha$ helix of the Cll homeodomain toward Al and DNA by this interaction, thereby increasing the contact surface area between the third $\alpha$ helix of the Cll homeodomain and the major groove of DNA. This interaction is thought to support the stabilization and localization of the third $\alpha$ helix of the Cll homeodomain to maximize the cooperative-binding affinity of $\mathrm{Al}$ and $\mathrm{Cll}$.

\section{Cooperative DNA-binding mechanism of Al and CII}

The extended conserved regions of the $\mathrm{Cll}$ homeodomain are indispensable to the cooperative DNA-binding mechanism of $\mathrm{Al}$ and Cll. The importance of the extended $\mathrm{N}$-terminal arm is also confirmed in the human homologue of Cll, Hox11L1. The EMSA analysis showed that both of the extended conserved regions are indispensable to the cooperative-binding mechanism of $\mathrm{Al}$ and Cll. These extensions are the characteristic features of Cll-type homeodomain proteins. Although Hox11L1, which is a human homologue of Cll, possesses a conserved YPMW motif-like Hox proteins, Cll and its homologues of insecta (Anopheles gambiae, Apis mellifera, and so on) do not possess this sequence motif. The Cll homeodomain would have evolved in a different way from other homeodomain proteins and obtained a Cll-specific function, that is, the ability to bind DNA cooperatively with Al.

This cooperative mechanism is quite different from those observed in the earlier ternary complex structures of homeodomains and DNA. The most important part of this finding is that the residues in the extended conserved regions of the homeodomain are used in the sequence-recognition mechanism to increase the sequence specificity of the cooperative DNA binding. In general, homeodomain proteins are believed to recognize DNA sequences using their homeodomain or additional DNA-binding domain, and the sequence preferences of the homeodomain regions have been well characterized (Berger et al, 2008; Noyes et al, 2008). In the homeodomain family, there are subfamilies that possess extended conserved regions around the homeodomain (DuBoule, 1994). Our results suggest that these extended conserved regions may promote the diversity of recognition sequences of homeodomains by the cooperative DNA-binding mechanisms with other homeodomain proteins.

\section{Materials and methods}

\section{Protein expression and purification}

Gene fragments of Al, Cll, CART1, and Hox11L1 were obtained by PCR from cDNA. Amplified gene fragments were cloned into the T7 polymerase-based protein expression vectors pET26b and pET28a. The expression vectors were transformed into Escherichia coli strain Rosetta (DE3) cells for protein expression. Transformants were cultivated at $37^{\circ} \mathrm{C}$ in LB medium until the optical density at $600 \mathrm{~nm}$ reached 0.6. The protein expressions were induced by the addition of IPTG at a final concentration of $1 \mathrm{mM}$. Cultivations were further continued at $25^{\circ} \mathrm{C}$ for $16 \mathrm{~h}$ to allow the accumulation of expressed proteins. Each construct was purified by cation exchange chromatography using CM Sepharose and Resource S (GE Healthcare) columns and dialysed against $10 \mathrm{mM}$ Tris- $\mathrm{HCl}(\mathrm{pH} 8.0)$ and $200 \mathrm{mM} \mathrm{NaCl}$.

\section{Protein-DNA-binding assays}

The $5^{\prime}$-FITC-labelled 30-mer dsDNA (5'-FITC-AAAGTTTCTTAAT TAATTGCTAAGCCAAAA-3'; the recognition sequence of $\overline{\mathrm{Al} \text { and }}$ Cll is underlined) for the DNA-binding assay was designed as described earlier (Kojima et al, 2005). Each protein construct and dsDNA were mixed and incubated in a buffer containing $20 \mathrm{mM}$ Tris- $\mathrm{HCl}$ (pH 7.5), $100 \mathrm{mM} \mathrm{KCl}, 0.25 \mathrm{mg} / \mathrm{ml} \mathrm{BSA}, 0.1 \% \mathrm{NP}-40$, and $0.2 \mathrm{mg} / \mathrm{ml}$ poly $(\mathrm{dI}-\mathrm{dC}) \times$ poly $(\mathrm{dI}-\mathrm{dC})$ for $60 \mathrm{~min}$ at $4{ }^{\circ} \mathrm{C}$. Bound and unbound DNAs were separated on a $12 \%$ polyacrylamide gel, and fluorescence was measured by an LAS4000 Mini system (Fujifilm, Tokyo, Japan). The protein composition of the binding reactions and the labelled DNA probe used are described in the figure legends. $K_{\mathrm{D}} \mathrm{S}$ values were measured by at least four independent experiments, each containing at least eight protein concentration data points fit to nonlinear hyperbolic curves using Prism4 software (GraphPad Software Inc., San Diego, CA).

\section{Crystallization and structure determination}

All crystallization experiments were performed using the sittingdrop vapour-diffusion method. Crystals of the Al and Hox11L1 homeodomains were obtained in a reservoir solution containing $0.1 \mathrm{M}$ acetate buffer (pH 4.8), $0.1 \mathrm{M} \mathrm{CdCl}_{2}$, and $30 \%$ PEG400; and $0.1 \mathrm{M}$ Tris- $\mathrm{HCl}(\mathrm{pH} 8.6), 0.2 \mathrm{M} \mathrm{Li}_{2} \mathrm{SO}_{4}$, and $35 \%$ PEG4000, respectively.

For co-crystallization of the Al-DNA complex, 14-mer dsDNA (5'-GGGTTTAATTAGGG-3') was mixed with an equimolar amount of Al-HD. The binary complex solution was concentrated to $300 \mu \mathrm{M}$ for crystallization. Binary complex crystals were obtained in a reservoir solution containing $0.1 \mathrm{M}$ Tris- $\mathrm{HCl}$ ( $\mathrm{pH} 8.5$ ), $0.2 \mathrm{M}$ sodium acetate trihydrate, and $26 \%$ PEG4000.

For co-crystallization of the Al-Cll-DNA complex, 17-mer dsDNA (5'-GGCTTAATTAATTGCGG-3') was mixed with an equimolar amount of Al-HD and Cll-N2C3. The ternary complex solution was concentrated to $250 \mu \mathrm{M}$ for crystallization. Ternary complex crystals were obtained in a reservoir solution containing $0.2 \mathrm{M}$ sodium malonate (Ph 7.0), $18 \%$ PEG3350, and $0.01 \mathrm{M}$ spermidine within 2 weeks.

X-ray diffraction data sets of the Al homeodomain, the Hox11L1 homeodomain, the binary complex of Al-DNA, and the ternary complex of Al-Cll-DNA were collected at beamline AR-NW12 at the Photon Factory (Tsukuba, Japan). The crystal of the Al home-

Table I Data collection and refinement statistics of the Al-Cll-DNA complex

\begin{tabular}{lc}
\hline Data collection & \\
Space group & \\
Cell dimensions & \\
$a, b, c(\AA)$ & $70.93,85.40,110.68$ \\
Observed reflections & 266303 \\
Unique reflections & 18995 \\
Resolution $(\AA)$ & $20.0-2.70(2.77-2.70)^{\mathrm{a}}$ \\
$R_{\text {merge }}(\%)$ & $6.7(59.2)$ \\
$I / \sigma I$ & $27.10(4.24)$ \\
Completeness $(\%)$ & $99.6(100)$ \\
Redundancy & $14.0(10.1)$ \\
& \\
Refinement & \\
$R / R_{\text {free }}(\%)$ & $23.4 / 28.2$ \\
No. of atoms & \\
Protein & 2286 \\
DNA & 1382 \\
r.m.s.d. & \\
Bond length $(\AA)$ & \\
Bond angle (deg) & 0.011 \\
Ramachandran plot & 1.769 \\
Favoured region $(\%)$ & \\
Allowed region $(\%)$ & \\
Outer region $(\%)$ & 94.5 \\
\hline
\end{tabular}

${ }^{\mathrm{a}}$ Values in parentheses are for the highest-resolution shell. 
odomain was diffracted to a resolution of $1.00 \AA$. The crystal of the Al homeodomain belonged to space group $P 3_{2} 21$ with unit cell dimensions of $a=b=45.81$ and $c=48.98 \AA$. The crystal of the Hox 11L1 homeodomain was diffracted to a resolution of $1.54 \AA$. The crystal of the Hox11L1 homeodomain belonged to space group $C 2$ with unit cell dimensions of $a=73.06, b=33.17, c=34.43 \AA$, and $\beta=102.12^{\circ}$. The crystal of the Al-DNA binary complex was diffracted to a resolution of $2.25 \AA$. The complex crystal belonged to space group $P 4_{3} 2_{1} 2$ with unit cell dimensions of $a=b=42.35$ and $c=162.73 \AA$. The crystal of the Al-Cll-DNA ternary complex was diffracted to a resolution of $2.70 \AA$. The complex crystal belonged to space group $P 2_{1} 2_{1} 2_{1}$ with unit cell dimensions of $a=70.9, b=85.4$, and $c=110.7 \AA$. All X-ray diffraction data were integrated and scaled with the program XDS (Kabsch, 1993). Data collection statistics are summarized in Table I and Supplementary Table I.

The structures of $\mathrm{Al}$ and Hox11L1 were determined by the molecular replacement method using the program MOLREP (Vagin and Teplyakov, 1997) with the coordinates of the homeodomain structure of Pax (PDB ID: 1FJL) (Wilson et al, 1995) and HoxA9 (PDB ID: 1PUF) (LaRonde-LeBlanc and Wolberger, 2003) as templates, respectively. Initial models were refined and manually rebuilt with the programs Refmac5 (Murshudov et al, 1997) and XtalView (McRee, 1999).

The binary complex structure of Al-DNA and the ternary complex structure of Al-Cll-DNA were determined by the molecular replacement method using the program MOLREP with the coordinates of Al, Hox11L1, and dsDNA obtained from the HoxA9Pbx1-DNA structure (LaRonde-LeBlanc and Wolberger, 2003). The initial model was refined and manually rebuilt with the programs Refmac5 and XtalView. The structures were validated by the programs PROCHECK (Laskowski et al, 1993) and Rampage (Lovell et al, 2003). The refinement statistics are summarized in Table I and Supplementary Table I.

\section{References}

Berger M, Badis G, Gehrke A, Talukder S, Philippakis A, Peña-Castillo L, Alleyne T, Mnaimneh S, Botvinnik O, Chan E, Khalid F, Zhang W, Newburger D, Jaeger S, Morris Q, Bulyk M, Hughes $\mathrm{T}$ (2008) Variation in homeodomain DNA binding revealed by high-resolution analysis of sequence preferences. Cell 133: $1266-1276$

Bertolino E, Reimund B, Wildt-Perinic D, Clerc R (1995) A novel homeobox protein which recognizes a TGT core and functionally interferes with a retinoid-responsive motif. J Biol Chem 270: $31178-31188$

Beverdam A, Brouwer A, Reijnen M, Korving J, Meijlink F (2001) Severe nasal clefting and abnormal embryonic apoptosis in Alx3/ Alx4 double mutant mice. Development 128: 3975-3986

Billeter M, Qian Y, Otting G, Müller M, Gehring W, Wüthrich K (1993) Determination of the nuclear magnetic resonance solution structure of an Antennapedia homeodomain-DNA complex. J Mol Biol 234: 1084-1093

Brouwer A, ten Berge D, Wiegerinck R, Meijlink F (2003) The OAR/ aristaless domain of the homeodomain protein Cart1 has an attenuating role in vivo. Mech Dev 120: 241-252

Campbell G (2005) Regulation of gene expression in the distal region of the Drosophila leg by the Hox11 homolog, C15. Dev Biol 278: 607-618

Chang CP, Shen WF, Rozenfeld S, Lawrence HJ, Largman C, Cleary ML (1995) Pbx proteins display hexapeptide-dependent cooperative DNA binding with a subset of Hox proteins. Genes Dev 9: 663-674

Cheng L, Arata A, Mizuguchi R, Qian Y, Karunaratne A, Gray P, Arata S, Shirasawa S, Bouchard M, Luo P, Chen C, Busslinger M, Goulding M, Onimaru H, Ma Q (2004) Tlx3 and Tlx1 are postmitotic selector genes determining glutamatergic over GABAergic cell fates. Nat Neurosci 7: 510-517

Collaborative Computational Project Number 4 (1994) The CCP4 suite: programs for protein crystallography. Acta Crystallogr D Biol Crystallogr 50: 760-763

Crothers DM, Shakked Z (1999) DNA bending by adenine-thymine tracts. In Oxford Handbook of Nucleic Acid Structures, Neidle S (ed), pp 455-470. London: Oxford University Press

\section{Computational}

The structures of $\mathrm{Al}$, Hox11L1, and the ternary complex were analysed using a set of computer programs: Pymol (http:// pymol.sourceforge.net/) to depict the structure, Curves + (Lavery et al, 2009) to analyse the DNA geometry, Surface in CCP4 (Collaborative Computational Project Number 4, 1994) for calculation of the protein surface area, and Dalilite (Holm and Park, 2000) for the superposition of molecules.

\section{Accession numbers}

The coordinates have been deposited in the RCSB Protein Data Bank with the accession codes 3A02 (Al homeodomain), 3A03 (Hox11L1 homeodomain), 3LNQ (Al-DNA), and 3A01 (Al-Cll-DNA).

\section{Supplementary data}

Supplementary data are available at The EMBO Journal Online (http://www.embojournal.org).

\section{Acknowledgements}

The synchrotron-radiation experiments were performed at beamline AR-NW12 at the Photon Factory (Proposal No. 2006G150). This work was supported in part by the National Project on Protein Structural and Functional Analyses and the Targeted Proteins Research Program (TPRP) of the Ministry of Education, Culture, Sports, Science, and Technology, Japan.

\section{Conflict of interest}

The authors declare that they have no conflict of interest.

Dear T, Sanchez-Garcia I, Rabbitts T (1993) The HOX11 gene encodes a DNA-binding nuclear transcription factor belonging to a distinct family of homeobox genes. Proc Natl Acad Sci USA 90: $4431-4435$

DuBoule D (ed) (1994) Guidebook to the Homeobox Genes. Oxford: Oxford University Press

Fraenkel E, Pabo C (1998) Comparison of X-ray and NMR structures for the Antennapedia homeodomain-DNA complex. Nat Struct Biol 5: 692-697

Fraenkel E, Rould M, Chambers K, Pabo C (1998) Engrailed homeodomain-DNA complex at 2.2 A resolution: a detailed view of the interface and comparison with other engrailed structures. $J \mathrm{Mol}$ Biol 284: 351-361

Gehring WJ, Affolter M, Burglin T (1994a) Homeodomain proteins. Annu Rev Biochem 63: 487-526

Gehring WJ, Qian YQ, Billeter M, Furukubo-Tokunaga K, Schier AF, Resendez-Perez D, Affolter M, Otting G, Wuthrich K (1994b) Homeodomain-DNA recognition. Cell 78: 211-223

Goutte C, Johnson A (1993) Yeast a1 and alpha 2 homeodomain proteins form a DNA-binding activity with properties distinct from those of either protein. $J$ Mol Biol 233: 359-371

Hatano M, Aoki T, Dezawa M, Yusa S, Iitsuka Y, Koseki $H$, Taniguchi M, Tokuhisa T (1997) A novel pathogenesis of megacolon in Ncx/Hox11L.1 deficient mice. J Clin Invest 100: 795-801

Hatano M, Roberts C, Minden M, Crist W, Korsmeyer S (1991) Deregulation of a homeobox gene, HOX11, by the t $(10 ; 14)$ in T cell leukemia. Science 253: 79-82

Hirsch J, Aggarwal A (1995) Structure of the even-skipped homeodomain complexed to AT-rich DNA: new perspectives on homeodomain specificity. EMBO J 14: 6280-6291

Holm L, Park J (2000) DaliLite workbench for protein structure comparison. Bioinformatics 16: 566-567

Hovde S, Abate-Shen C, Geiger J (2001) Crystal structure of the Msx-1 homeodomain/DNA complex. Biochemistry 40: 12013-12021

Joshi R, Passner J, Rohs R, Jain R, Sosinsky A, Crickmore M, Jacob V, Aggarwal A, Honig B, Mann R (2007) Functional specificity of a 
Hox protein mediated by the recognition of minor groove structure. Cell 131: 530-543

Kabsch W (1993) Automatic processing of rotation diffraction data from crystals of initially unknown symmetry and cell constants. J Appl Cryst 26: 795-800

Kanzler B, Dear T (2001) Hox11 acts cell autonomously in spleen development and its absence results in altered cell fate of mesenchymal spleen precursors. Dev Biol 234: 231-243

Ke A, Wolberger C (2003) Insights into binding cooperativity of MATa1/MATalpha2 from the crystal structure of a MATa1 homeodomain-maltose binding protein chimera. Protein Sci 12: 306-312

Kennedy M, Gonzalez-Sarmiento R, Kees U, Lampert F, Dear N, Boehm T, Rabbitts T (1991) HOX11, a homeobox-containing T-cell oncogene on human chromosome 10q24. Proc Natl Acad Sci U S A 88: $8900-8904$

Klemm JD, Rould MA, Aurora R, Herr W, Pabo CO (1994) Crystal structure of the Oct-1 POU domain bound to an octamer site: DNA recognition with tethered DNA-binding modules. Cell 77: $21-32$

Knoepfler P, Kamps M (1995) The pentapeptide motif of Hox proteins is required for cooperative DNA binding with Pbxl, physically contacts Pbx1, and enhances DNA binding by Pbx1. Mol Cell Biol 15: 5811-5819

Kojima T, Tsuji T, Saigo K (2005) A concerted action of a paired-type homeobox gene, aristaless, and a homolog of Hox11/tlx homeobox gene, clawless, is essential for the distal tip development of the Drosophila leg. Dev Biol 279: 434-445

Kuijper S, Beverdam A, Kroon C, Brouwer A, Candille S, Barsh G, Meijlink F (2005) Genetics of shoulder girdle formation: roles of Tbx15 and aristaless-like genes. Development 132: 1601-1610

LaRonde-LeBlanc NA, Wolberger C (2003) Structure of HoxA9 and Pbx1 bound to DNA: Hox hexapeptide and DNA recognition anterior to posterior. Genes Dev 17: 2060-2072

Laskowski RA, MacArthur MW, Moss DS, Thornton JM (1993) PROCHECK: a program to check the stereochemical quality of protein structures. J Appl Cryst 26: 283-291

Laughon A (1991) DNA binding specificity of homeodomains. Biochemistry 30: 11357-11367

Li T, Stark MR, Johnson AD, Wolberger C (1995) Crystal structure of the MATa1/MAT alpha 2 homeodomain heterodimer bound to DNA. Science 270: 262-269

Lavery R, Moakher M, Maddocks J, Petkeviciute D, Zakrzewska K (2009) Conformational analysis of nucleic acids revisited: curves + . Nucleic Acids Res 37: 5917-5929

Lovell SC, Davis IW, Arendall III WB, de Bakker PI, Word JM, Prisant MG, Richardson JS, Richardson DC (2003) Structure validation by Calpha geometry: phi, psi and Cbeta deviation. Proteins 50: 437-450

Mann RS, Chan SK (1996) Extra specificity from extradenticle: the partnership between HOX and PBX/EXD homeodomain proteins. Trends Genet 12: 258-262

McRee DE (1999) XtalView/Xfit-a versatile program for manipulating atomic coordinates and electron density. J Struct Biol 125: 156-165

Murshudov GN, Vagin AA, Dodson EJ (1997) Refinement of macromolecular structures by the maximum-likelihood method. Acta Crystallogr D Biol Crystallogr 53: 240-255

Neuteboom ST, Murre C (1997) Pbx raises the DNA binding specificity but not the selectivity of antennapedia Hox proteins. Mol Cell Biol 17: 4696-4706
Noyes M, Christensen R, Wakabayashi A, Stormo G, Brodsky M, Wolfe S (2008) Analysis of homeodomain specificities allows the family-wide prediction of preferred recognition sites. Cell 133: 1277-1289

Passner JM, Ryoo HD, Shen L, Mann RS, Aggarwal AK (1999) Structure of a DNA-bound ultrabithorax-extradenticle homeodomain complex. Nature 397: 714-719

Phillips C, Stark M, Johnson A, Dahlquist F (1994) Heterodimerization of the yeast homeodomain transcriptional regulators alpha 2 and al induces an interfacial helix in alpha 2. Biochemistry 33: 9294-9302

Piper DE, Batchelor AH, Chang CP, Cleary ML, Wolberger C (1999) Structure of a HoxB1-Pbx1 heterodimer bound to DNA: role of the hexapeptide and a fourth homeodomain helix in complex formation. Cell 96: 587-597

Qian YQ, Billeter M, Otting G, Muller M, Gehring WJ, Wuthrich K (1989) The structure of the Antennapedia homeodomain determined by NMR spectroscopy in solution: comparison with prokaryotic repressors. Cell 59: $573-580$

Qu S, Tucker S, Zhao Q, deCrombrugghe B, Wisdom R (1999) Physical and genetic interactions between Alx4 and Cart1. Development 126: 359-369

Roberts C, Shutter J, Korsmeyer S (1994) Hox11 controls the genesis of the spleen. Nature 368: 747-749

Roberts C, Sonder A, Lumsden A, Korsmeyer S (1995) Development expression of Hox11 and specification of splenic cell fate. Am J Pathol 146: 1089-1101

Salvati P, Ranford P, Ford J, Kees U (1995) HOX11 expression in pediatric acute lymphoblastic leukemia is associated with T-cell phenotype. Oncogene 11: 1333-1338

Shirasawa S, Yunker A, Roth K, Brown G, Horning S, Korsmeyer S (1997) Enx (Hox11L1)-deficient mice develop myenteric neuronal hyperplasia and megacolon. Nat Med 3: 646-650

Slupsky C, Sykes D, Gay G, Sykes B (2001) The HoxB1 hexapeptide is a prefolded domain: implications for the Pbx1/Hox interaction. Protein Sci 10: 1244-1253

Stark MR, Johnson AD (1994) Interaction between two homeodomain proteins is specified by a short C-terminal tail. Nature 371: 429-432

Tucker-Kellogg L, Rould M, Chambers K, Ades S, Sauer R, Pabo C (1997) Engrailed (Gln50-> Lys) homeodomain-DNA complex at 1.9 A resolution: structural basis for enhanced affinity and altered specificity. Structure 5: 1047-1054

Vagin A, Teplyakov A (1997) MOLREP: an automated program for molecular replacement. J Appl Cryst 30: 1022-1025

White R (1994) Homeodomain proteins. Homeotic genes seek partners. Curr Biol 4: 48-50

Wilson D, Sheng G, Lecuit T, Dostatni N, Desplan C (1993) Cooperative dimerization of paired class homeo domains on DNA. Genes Dev 7: 2120-2134

Wilson DS, Guenther B, Desplan C, Kuriyan J (1995) High resolution crystal structure of a paired (Pax) class cooperative homeodomain dimer on DNA. Cell 82: 709-719

Wolberger C, Vershon AK, Liu B, Johnson AD, Pabo CO (1991) Crystal structure of a MAT alpha 2 homeodomain-operator complex suggests a general model for homeodomain-DNA interactions. Cell 67: 517-528

Zhao G, Eberspaecher H, Seldin M, de Crombrugghe B (1994) The gene for the homeodomain-containing protein Cart-1 is expressed in cells that have a chondrogenic potential during embryonic development. Mech Dev 48: 245-254 